\title{
$1{ }^{\circ}$ CONAERG \\ CONGRESSO INTERNACIONAL DE ERGONOMIA APLICADA
}

\section{ASPECTOS ANTROPOMÉTRICOS DO PÉ E SUA INFLUÊNCIA \\ NA ERGONOMIA DO CALÇADO FEMININO}

\author{
Pedro Ferreira Reis (1); \\ Any Karoline Birnfeldt (2); \\ Bruna Homem de Souza Osman (3).
}

(1) Centro Universitário Dinâmica das Cataratas - UDC

e-mail: fisioterapeutadotrabalho@hotmail.com

(2) Centro Universitário Dinâmica das Cataratas - UDC

e-mail: any kb96@hotmail.com

3) Centro Universitário Dinâmica das Cataratas - UDC

e-mail: brunaosman@gmail.com

\begin{abstract}
RESUMO
Os aspectos que mais contribuem para o desconforto dos pés é a ergonomia do caçado e a antropometria do pé. O objetivo da pesquisa foi verificar a influência da antropometria do pé na ergonomia do calçado. Esta pesquisa de característica descritiva quantitativa e exploratória foi realizada com 24 mulheres e faixa etária de 15 a 50 anos, sendo efetivada através de um questionário com perguntas objetivas sobre a presença de fatores de desconforto. Os resultados foram $33 \%$ com número 37 , e $20 \% 36$. O formato de pé apresentou $58 \%$ romano, $20 \%$ egípcio e $12,5 \%$ quadrado. Quanto aos desconfortos $45 \%$ apresentaram dores nos dedos, $37 \%$ dores no metatarso. Já $75 \%$ afirmaram que o calçado novo provoca danos, destacando bolhas. Conclui-se com esta pesquisa que a antropometria do pé afeta a ergonomia do calçado.
\end{abstract}

Palavras chaves: Antropometria; Ergonomia; Calçados.

\begin{abstract}
The aspects that contribute to the discomfort of the feet is the ergonomics of the hunted and the anthropometry of the foot. The objective of the research was to investigate the influence of foot anthropometry in ergonomic footwear. This quantitative and exploratory descriptive characteristic of research was conducted with 24 women and aged 15-50 years, and carried through a questionnaire with objective questions about the presence of discomfort factors. The results were $33 \%$ by number 37 and 20\% 36. The foot format in 58\% Roman, 20\% and $12.5 \%$ Egyptian square. As for the discomforts $45 \%$ had pain in the fingers, $37 \%$ pain in the metatarsal. Already $75 \%$ said that the new footwear causes damage, highlighting bubbles. The conclusion of this research that anthropometry foot affects the ergonomics of footwear.
\end{abstract}

Key words: anthropometry; Ergonomics; Shoes. 


\section{INTRODUÇÃO}

Tida como base para o desenvolvimento do projeto em questão, os aspectos antropométricos são alvos de vários estudos para melhor compreensão das medidas humanas para a confecção de produtos, tais como, os calçados.

São muitas as dificuldades de se encontrar um calçado que se adeque aos pés sem que cause nenhum dano aos mesmos. Os aspectos que mais contribuem para o desconforto dos pés nos calçados é geralmente a questão de numeração, do tipo de pisada e formato do pé e a presença de aspectos individuais que causam desconforto como joanete, suor e mau odor assim como doenças (CASTRO, 2007).

Contudo, a relação produto e usuário são qualificados não só pelo conforto, mas pelas mulheres principalmente, pelo design. Sendo dois aspectos nem sempre ligados um ao outro. Em defesa do consumidor e de produtos qualificados às suas necessidades, as empresas procuram aliar design e ergonomia em seus calçados, sendo a ergonomia o estudo entre homem e trabalho, seu ambiente. Uma ciência que também se baseia na anatomia e psicologia (BERWANGER, 2011).

Os primeiros vestígios de calçados surgiram a partir do momento que o homem sai para a caça, suprindo a necessidade de proteção dos pés. Paralelo a isto, cada região com seu clima e solo, foi aderindo ornamentos que atendessem as necessidades geográficas de cada região. Tendo assim materiais próprios como no Egito, uma região quente, usava-se muita palha para a confecção, já em Roma indícios apontam que o calçado já servira para compor a roupa (VALIM, 2006). Segundo este mesmo autor, a procura significativa por este artefato começou pela Europa, onde o design tinha um valor maior agregado ao sapato.

O calçado teve muitas mudanças baseadas em decretos reais principalmente na Europa, porém a primeira produção de calçados em massa, de como temos atualmente, data de 1642, na Inglaterra, onde foram produzidas botas para o exército, mas foi após a Revolução Industrial da Inglaterra que a produção se intensificou (PASSOS; KANAMARU, 2013).

Deste ponto de partida, a diferenciação do pé esquerdo para o direito foi suprida, em que os estadunidenses criaram um sapato torto, que se adequasse à diferenciação. $A$ partir do século $\mathrm{XX}$ em diante, o que presenciamos é uma variedade imensa de modelos e materiais. Um setor baseado na produção, funcionalidade, ergonomia, design e distribuição, e ainda manter o simbolismo característico do calçado com o ser humano (NOVAES, 2006).

Projetados apenas para a função de proteção, os calçados passaram de meros artefatos e tornaram-se parte da transformação de sociedades e transformações psicológicas do ser humano (PETTER; WOLFF, 2015).

Uma vez escondidos e hoje mais do que explícitos, os calçados podem remeter seu usuário ao passado ou ao futuro. Transformam e descrevem uma personalidade, e 
além de tudo ainda mantém conceitos da moda atual e suas últimas tendências do mercado (VALENTE, 2007).

Contudo, perante a principal função dos pés de sustentação do corpo, é possível fazer uma análise de toda sua extensão para assim obter resultados que influenciem na confecção de um calçado confortável com tal de melhorar a saúde dos pés (CEZAR; MORO; JORGE; REIS, 2003). Estes autores ainda complementam com a afirmação de que como o pé tem a função de sustentação, essa função é exercida por duas principais regiões do pé, a região do calcâneo que se refere ao apoio do pé, e a parte referente à cabeça do metatarso, responsável pela marcha humana.

Na medida em que o pé vai tornando-se fixo em relação ao seu formato, é necessário ter o cuidado para adquirir calçados que possam influenciar nesse desenvolvimento de ossificação e da estrutura da cartilagem. Contudo a presente padronização de medidas tende a desconsiderar aspectos ergonômicos individuais dos pés como formatos ou medidas, resultando numa diferença de medidas que pode ser considerada maior ainda quando diferenciada por regiões (BOZANO; OLIVEIRA, 2011).

$\mathrm{Na}$ busca de aliar o conforto e o design e proporcionar a satisfação do consumidor, muitas empresas procuram pelo profissional de design de sapatos, pois a mulher já não é mais uma escrava da moda, para que esse profissional alie aspectos de conforto de uma maneira criativa e inovadora (ABICALÇADOS; PSI; APEX, 2001).

Os aspectos importantes a serem analisados na individualidade da saúde dos pés são os tipos de pé, podendo ser classificados em normais, onde há uma ligação entre o ante pé e o calcanhar; o pé côncavo, onde a ligação com o ante pé é mínima ou pode não existir; e o pé chato, onde a superfície inteira da sola do pé atinge o chão e o formato de pé classificados em grego, romano e egípcio onde cada formato é resultado da análise da posição dos dedos do pé (VALENTE, 2007). Este mesmo autor afirma ainda que outro problema muito comum pelos usuários é o hálux valgo mais conhecida como joanete, é ocasionada por um desvio lateral do grande artelho, uma pressão que pode ser aumentada usando calçados com bico, gerando uma piora na saúde dos pés.

É importante destacar que o calçado brasileiro é construído, seguindo as normas brasileiras, nas quais a ABNT NBR 14834:2008 determina o conforto do calçado nos requisitos e ensaio; ABNT NBR 14835:2008 a massa do calçado; ABNT NBR 14836:2008 a dinâmica a distribuição da pressão plantar; ABNT NBR 14838:2008 o índice de amortecimento do calçado; ABNT NBR 14837:2008 a temperatura interna do calçado; ABNT NBR 14839:2008 o índice de pronação do calçado e ABNT NBR 14840:2008 os níveis de percepção do calce. Neste sentido a resposta levantada para esses problemas comuns nos pés em decorrência do calçado é de que a produção massificada torna o produto mais barato, porém o estudo mais aprofundado $\mathrm{e}$ levantamento de tecnologias para suprir essas necessidades torna o produto mais caro, tornando inviável a produção. Contudo a população brasileira leva culpa em parte, pois não exige muito perante as marcas como também por outro lado o preço dos calçados deve ser ponderado devido ao baixo poder aquisitivo de boa parte da 
população brasileira, sendo as principais barreiras entre conforto, calçado e consumidor (VALIM, 2006). Neste sentido, o objetivo do presente artigo é o desenvolvimento, pesquisa e análise de aspectos da antropometria dos pés e a consequente influência que exerce na ergonomia do calçado.

\section{MÉTODO}

Esta pesquisa de característica descritiva quantitativa e exploratória foi realizada com 24 mulheres e faixa etária de 15 a 60 anos, com pisada normal das cidades de Foz do Iguaçu e Santa Terezinha de Itaipu, estado do Paraná, Brasil. Todas as participantes assinaram o termo de consentimento livre e esclarecido (TCLE).

Os dados demográficos bem como os constrangimentos oriundos da usabilidade do calçado e formato do pé foram realizados através de um questionário com perguntas objetivas, sendo verificada a presença de dores e desconforto oriundos do calçado assim como a autoestima proporcionada por eles. Foram excluídos da pesquisa, portadores de pé plano, cavo, supinado e pronado.

Os resultados foram analisados através do programa Excel Four Windows e Bioestatic 5.0 .

A Antropometria do pé e tipo de pisada foi verificada através de um podoscópio de 220 Wolts da podotech apresentado na figura 1.

\section{Figura 1 - Podoscópio - Avaliação do Pé}

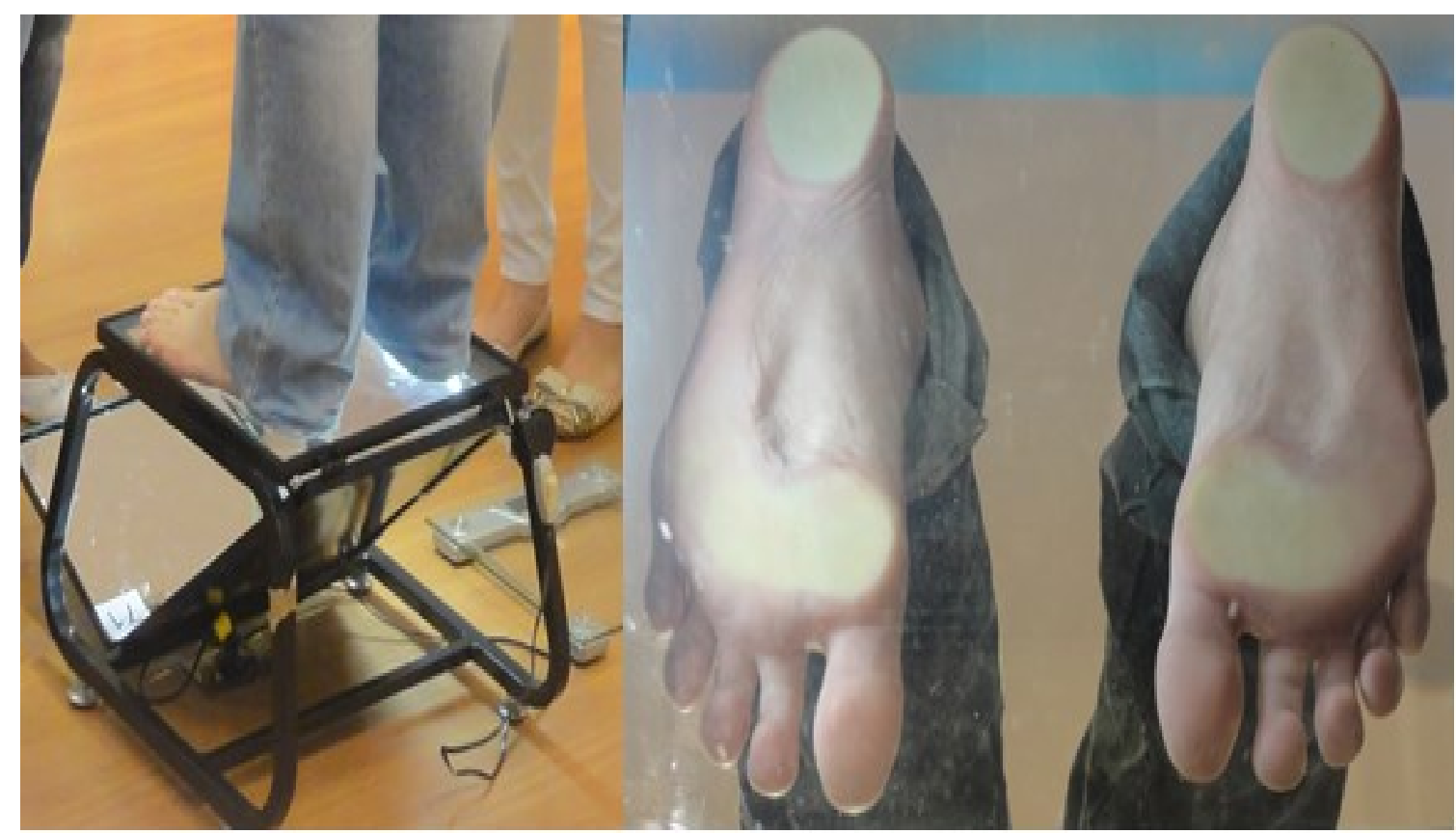




\section{RESULTADOS}

Com o objetivo de analisar as reações de autoestima, conforto e desconforto derivados do calçado em mulheres, foi realizada uma pesquisa quantitativa e exploratória com 24 mulheres.

Figura 2 - Percepção da autoestima e conforto em relação ao calçado

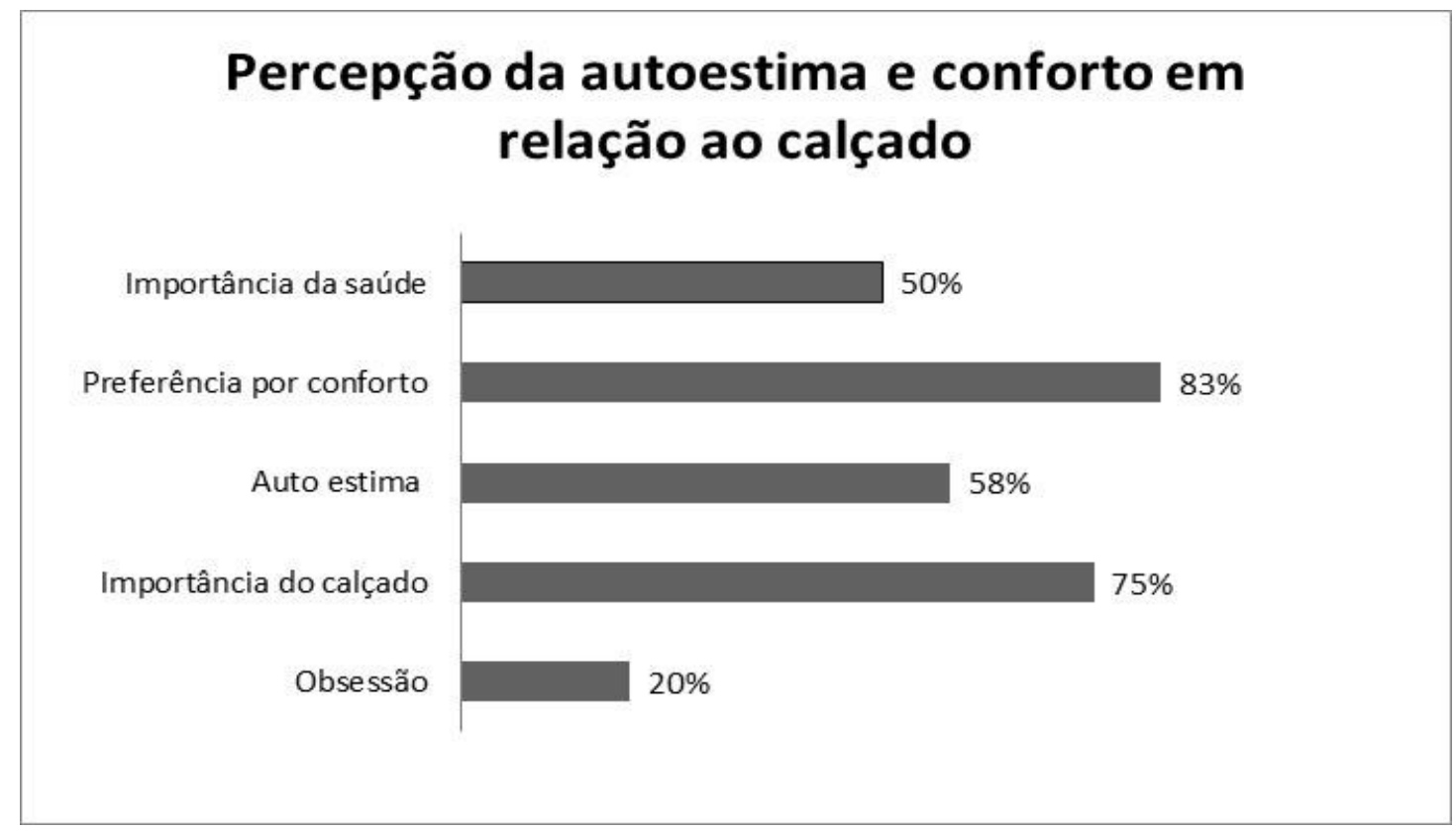

Conforme apresentado na figura 1, verificou-se que 50\% indicaram a importância da saúde no momento da compra do calçado e $83 \%$ proporcionam uma ênfase maior ao conforto, o que segundo Dresch; Campos (2012) é o item mais procurado pelas brasileiras na hora da compra sendo a prioridade do conforto referente à medidas individuais de cada pé. Neste sentido é importante destacar a importância da ergonomia do calçado na sua usabilidade. Assim nota-se que a padronização do número dos calçados brasileiros muitas vezes não satisfaz o usuário, os quais testam vários tipos, optando mais pelo conforto do que pela beleza.

A pesquisa ainda apresentou que $58 \%$ das mulheres tem a autoestima elevada na compra de um novo par de calçados tendo em vista que Valente (2007) afirma que os calçados refletem as sensações da usuária no momento além de permitir que este traduza a personalidade da mulher por meio de seus ornamentos, considerando também que Araujo (2014) descreve o aumento da autoestima derivado da atração que o calçado exerce na mulher, atração essa por vezes sexual ou relacionada ao poder.

No quesito importância do calçado, o resultado mostrou que $75 \%$ das entrevistadas consideram o calçado tão importante quanto uma peça de roupa, tendo o calçado como ornamento de questões físicas e de adaptação de estilo tendo tanta importância quanto qualquer peça de vestuário (NOVAES, 2006) 
Em termos de obsessão por calçados apenas $20 \%$ das entrevistadas se diz ser por vezes obsessiva por calçados, esse baixo número perante a obsessão por roupas se dá, conforme Araujo (2006) pelo fato das campanhas publicitárias de calçados não irem além com quesitos reais e simbólicos, deixando a desejar em inovação o que afeta o consumo.

Figura 3 - Formato de pé

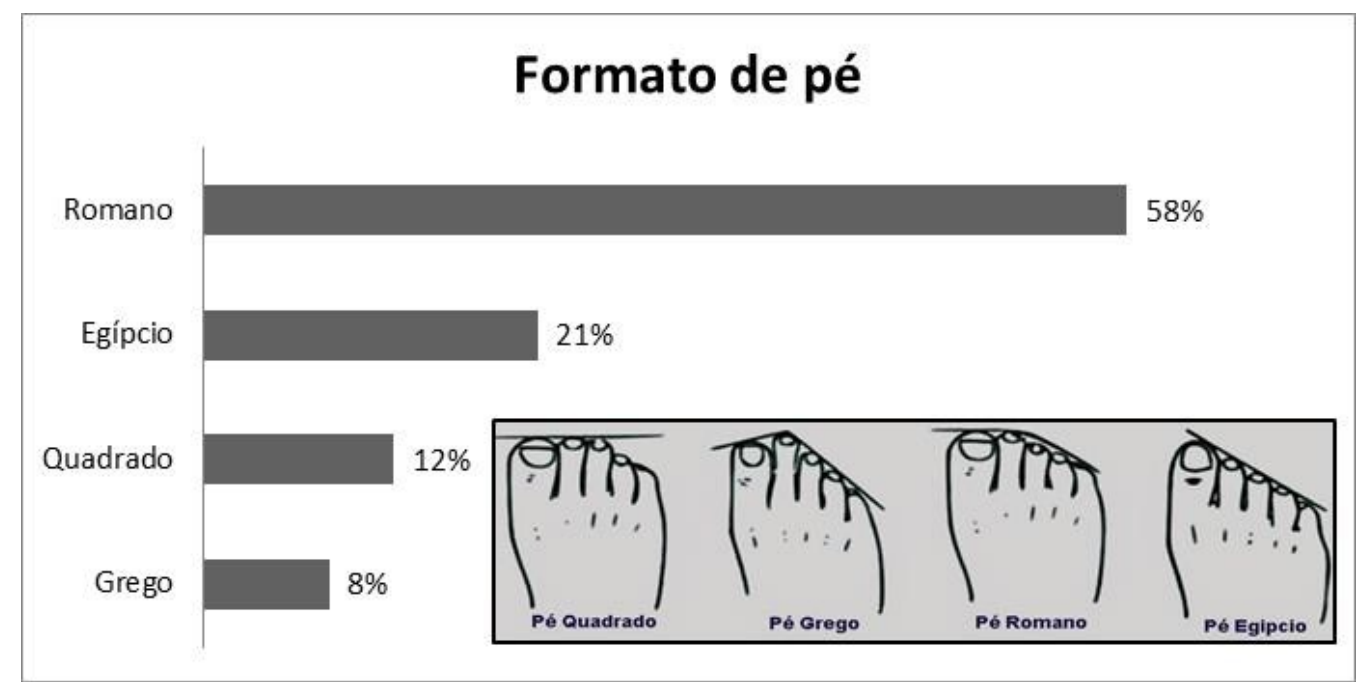

Na figura 3 é possível observar que os formatos de pé, sendo pé romano $58 \%$, pé egípcio $21 \%$, pé quadrado $12 \%$ e pé grego $8 \%$. Há uma ênfase ao número de pés romanos, contudo os demais formatos de pé constituem uma grande quantidade também, isso acontece, conforme Duarte; Emidio (2013), pelos aspectos antropométricos da sociedade brasileira e a decorrente miscigenação de povos e suas culturas.

Figura 4 - Percepção de conforto

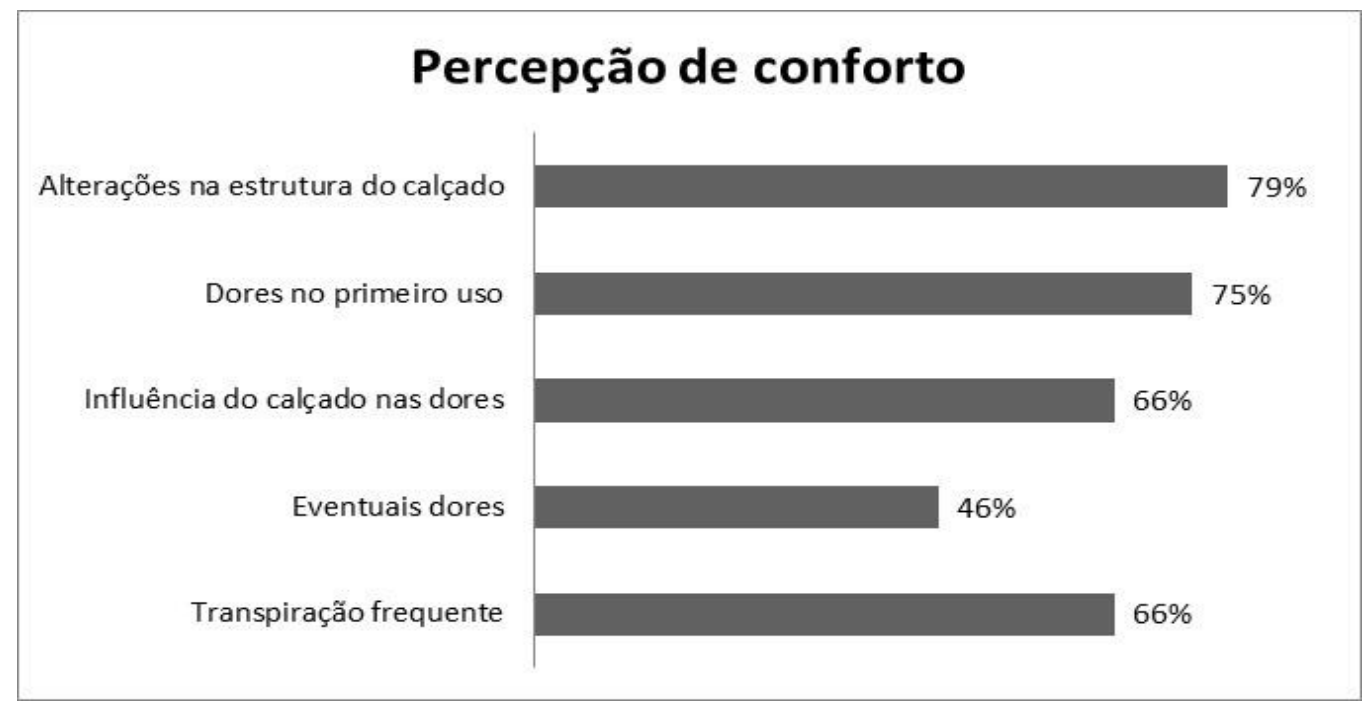


A figura 4 apresenta a percepção de conforto a qual interfere desde a estrutura deformada até eventuais dores. Constatou-se assim que $79 \%$ das entrevistadas percebem alterações na estrutura do calçado, isso acontece pelo fato de que muitos calçados padronizados não se adequam de forma correta ao tipo e formato de pé, como exemplo, não é comum a confecção de calçados para o tipo de pé chato, o que é uma deficiência da indústria (VALENTE, 2007).

$\mathrm{Na}$ questão de transpiração frequente $66 \%$ das entrevistadas dizem ter este tipo de problema ao usar um calçado, um fato que segundo Vargas (2011) não deveria ocorrer, pois o calçado deve constituir-se de materiais facilitadores da liberação de calor em climas quentes, para melhor transpiração dos pés sem o incomodo suor.

Em resultados apresentados em: eventuais dores $46 \%$ e dores durante o primeiro uso do calçado $75 \%$ condizem ao que Vargas (2011) afirma como problemas acarretados da confecção do calçado, nesta a influência do material utilizado, a modelagem e aspectos antropométricos são possíveis causadores de dores durante a marcha, ou o modelo do calçado como os pontiagudos podem justificar as dores, considerando que estes amontoam os dedos. Ainda segundo o autor, alguns dessas dores podem ser realmente problemas que são acarretados pelo uso de um calçado inadequado ao pé, como as entrevistadas afirmaram que de sua percepção consideram que o calçado pode influenciar nas dores, onde $66 \%$ afirmam isto. Conforme alerta Vargas (2011), o calçado pode afetar problemas que vão além de dores nos pés, como problemas na coluna, contudo isto deve ser verificado por um médico ortopedista para correções de uso e adequação da estrutura por meio de palmilhas.

\section{CONCLUSÃO}

A história da relação calçado e o feminino é antiga e reflete de todas as maneiras a necessidade de sentir-se elegante e de traduzir por meio do estilo do calçado a própria personalidade, os gostos e até mesmo a situação econômica.

Durante anos a única função do calçado foi a proteção dos pés nas diferentes mudanças climáticas, em prol de ajudar homens e mulheres durante a caça e plantação. A mudança na sociedade foi tornando o ornamento um produto mais respeitado, detalhado e diferenciado para as classes sociais, criando um vínculo ao desejo de poder transmitir o "eu" perante um calçado. Um objeto de desejo que nem sempre causou conforto e satisfação física na usuária.

A presente pesquisa buscou percorrer as linhas de insatisfação das usuárias a fim de mostrar o quão importante é o calçado para a autoestima da mulher, porém essa satisfação deve ser suprida com conforto. Há indústrias de calçados que envolvem seus produtos em estudos, tecnologia e conforto, resultando num ponto positivo para um futuro onde o acesso a um calçado adequado as medidas antropométricas e com ergonomia possam ser supridas e acessíveis também para as classes mais necessitadas da sociedade. 
Conclui-se que atualmente as indústrias de calçado em suas produções massificadas e de baixo custo fazem com que suas consumidoras paguem o preço por meio de dores e constrangimentos oriundos de suor e mau odor constantes devido ao uso errado de tecidos, modelagem ou de uma revisão antiga das medidas antropométricas dos pés das brasileiras. Notou-se que a ergonomia do calçado feminino precisa avançar para que as mulheres possam utilizar seus calçados com conforto, saúde e segurança.

\section{REFERENCIAS BIBLIOGRÁFICAS}

ABICALÇADOS; PSI; APEX. Estilismo e design - agregando valor ao mercado. V.3. n.2. p. 20 - 26. Rio Grande do Sul. 2001.

BERWANGER, E. G. Antropometria do pé feminino em diferentes alturas de salto como fundamento para conforto de calçados. Dissertação (Mestrado). p.18 - 32. Porto Alegre, 2011.

BOZANO, S.; OLIVEIRA, R de. Ergonomia dos calçados: os pés pedem conforto. n.9. p.5. Brusque, 2011.

CASTRO, A. de P. Características antropométricas dos pés de indivíduos idosos. Dissertação (Mestrado). P. 3 - 11. São Carlos: UFSCar, 2007.

CEZAR, M. R.; MORO, A. R. P.; JORGE, I. M. P.; REIS, P. F. Conforto em calçados atualidades. XXIII Encontro Nac. de Eng. De Produção - ENEGEP. p. 2 - 5. Ouro Preto, 2003.

NOVAES, G. C. de C. Os sapatos ao longo da existência humana e sua contemporaneidade. Antenna Web - Revista Digital do IBModa. v. 2. São Paulo, 2006.

PASSOS, V. T.; KANAMARU, A. T. A história do calçado: uma trajetória de design e ergonomia. VIII Colóquio de Moda. São Paulo, 2013.

PETTER, D.; WOLFF, F. Requisitos para desenvolver calçados de salto para mulheres com idade superiores aos 45 anos. ModaPalavra e-Periódico. v.15. p. 171. Santa Catarina, 2015.

VALENTE, E. L. Análise da percepção de desconforto/conforto e antropometria em calçados femininos: uma abordagem do design ergonômico. Dissertação (Mestrado). p. 1 - 32. Bauru, 2007.

VALIM, R. A. Incorporação de requisitos ergonômicos na indústria calçadista: um modelo em prol da saúde dos diabéticos. Dissertação (Mestrado). p. 57 - 74. Rio de Janeiro, 2006.

DRESCH, B; CAMPOS, G.F. A importância do conforto e do design no consumo de calçados femininos. VI ENEC $6^{\circ}$ Encontro Nacional de Estudos do Consumo. p. $7-12$. Rio de Janeiro, 2012. 
ARAUJO, A. L. F. Q. O sex appeal dos sapatos e o auto-conceito no feminino. Dissertação (Mestrado). p. 11 - 12. Lisboa, 2014.

NOVAES. G. C. de C. Os sapatos ao longo da existência humana e sua contemporaneidade. Antenna Web - Revista Digital do IBModa. v. 2. São Paulo, 2006.

ARAUJO, D. S. O consumo e a mulher consumidora. Comunicação, Mídia e Consumo. v. 3. n. 7. p. 149 - 164. São Paulo, 2006.

DUARTE, L. C.; EMIDIO, L. de F. B. A diversidade antropométrica brasileira e a importância da padronização de medidas no mercado da confecção: um olhar para o ecommerce. $9^{\circ}$ Colóquio de Moda. P. 3. Fortaleza, 2013.

VARGAS, I. P. R. Conforto no calçado feminino. Trabalho de Conclusão de Curso (TCC). p. 26- 29. Florianópolis, 2011. 